\title{
The No 'Ought' From 'Is' Argument: Faulty Thinking in Ethics and Social Science
}

\author{
James Doughney \\ Victoria University, Australia
}

\begin{abstract}
According to Hilary Putnam, the 'moral is clear: when we are dealing with any important value disagreement, we assume facts are irrelevant at our peril. No convincing logical reason can be given for the logical irrelevance of fact to value judgements, even if we accept the positivist conception of what a "fact" is.' (2002, p. 78) This paper explores why the dichotomies engendered by the 'positivist' approach - fact/value, positive/normative and descriptive/evaluative - are false. The main reason, the paper argues, is that the fundamental principle underlying the approach fails. This principle, the 'no ought from is argument' (or the NOFIA), is the formally structured argument that a value (ought) cannot logically be derived from a fact (is). The paper rejects the NOFIA and, especially, its iconic status in economics. Using criticisms of the NOFIA by John Searle, Amartya Sen, Hilary Putnam, Vivian Walsh and Julius Kovesi, as well as the critical realist method of explanatory critique, the paper argues for a form of moral realism.
\end{abstract}

\section{Introduction}

Value judgements, generations of students have been told authoritatively, are both non-factual and about ends such as social policy. ${ }^{1}$ Social scientists should not concern themselves with such matters in their day jobs. In their other lives they would, of course, have values: political, religious, social or whatever. However, these values are best left at the door of science, like muddy shoes and wet raincoats. Values have no place within objective social scientific research. To be scientific, social research must deal exclusively with facts and with the means of achieving ends that are given or assumed. We have heard this story many times before, with each discipline giving it a little twist to suit its subject matter and house lexicon. Ironically this core tale is normative. My italics above merely highlight the unreflective 'oughts' and 'ought nots' in the standard expositions.

A classical statement of the position is Lionel Robbins's 1932 An Essay on the Nature and Significance of Economic Science. Other social sciences have their equivalents but, because mainstream economics

Copyright (C) 2006 Victoria University. This document has been published as part of the Journal of Business Systems, Governance and Ethics in both online and print formats. Educational and non-profit institutions are granted a nonexclusive licence to utilise this document in whole or in part for personal or classroom use without fee, provided that correct attribution and citation are made and this copyright statement is reproduced. Any other usage is prohibited without the express permission of the is so vivid an example, I will quote Robbins here. I will also continue to use economics as an example in this paper. Robbins argues that it is not:

... in the least implied that economists should not deliver themselves on ethical questions ... On the contrary, it is greatly to be desired ... since only in this way

1 The author expresses appreciation to two anonymous referees for correcting errors and making helpful suggestions. The usual caveat, of course, applies. 
will they be in a position to appreciate the implications as regards given ends of problems which are put to them for solution ... Now, as regards the first type of difference [about given ends themselves], neither Economics nor any other science can provide any solvent. If we disagree about ends it is a case of thy blood or mine - or live and let live, according to the importance of the difference, or the relative strength of our opponents. But if we disagree about means, then scientific analysis can often help us to resolve our differences ... Surely ... it is worth while delimiting the neutral area of science from the more disputable area of moral and political philosophy. (Robbins 1935 [1932], pp. 149-51; original emphasis)

This long quotation is useful because it clearly delineates the three dichotomies engendered by mainstream approaches in the social sciences. First facts (descriptions, evidence, data etc.) are the raw material of social science. They are not the raw material of ethics (morals, political philosophy, policy etc.), though they might inform ethical deliberations. Second values are the raw material of ethics, and facts ultimately have no purchase here. As Robbins said above: 'If we disagree about ends it is a case of thy blood or mine - or live and let live, according to the importance of the difference, or the relative strength of our opponents'. Milton Friedman also put it bluntly in his influential essay, 'The methodology of positive economics'. Where arguments rested on 'fundamental differences in basic values' they were of a kind 'about which men [sic] can ultimately only fight' $(1953$, p. 5). Ipso facto values are not the raw material of social science and, though we all have values of some sort or another, we must quarantine them from our work. Third ends and means must be separate: values and ends go together, as do facts and means.

It is all very neat. The problem is that it is wrong, as I will show. Worse still, because it faulty, the approach leads to some very unsavoury outcomes. One of these is that supposedly neutral disciplines again economics is emblematic - are chock full of values dressed up as facts. Another is the illicit moral absolution supposed by carving off ends into the separate domain of values. 'Don't blame me guv, I'm just workin' to giv'n ends!' A third unsavoury outcome is in the domain of values itself, and it arises because the approach carves off facts. This is the problem of ethical or value relativism. Once we designate opinions as 'value judgements' it is as if they are given a warrant to be out of cognitive reach. Evidence is insufficient in evaluating value judgements per se. Any one person's opinion, despite being palpable nonsense or ethically dangerous, is as good as any other's. Values and preferences are relative to the person who holds them: ultimately they must be incommensurable.

Why are the dichotomies engendered by the mainstream approach flawed? One reason, the subject of this paper, is that the fundamental principle underlying the approach fails. This principle is the "no ought from is argument', or the NOFIA as I will call it from now on. The NOFIA will stand for the formal structure of the argument that a value (ought) cannot logically be derived from a fact (is). I will take the is-ought, fact-value, descriptive-evaluative and positive-normative pairs to state the same things here, despite there being subtle differences between each.

It is important to note that I will not discuss the separate problem of how social scientists' perspectives (and their values) may be secreted (ostensibly 'naturalised') within theories, explanations and statements. That is, I will not deal with the familiar argument (right so far as it goes) that social scientists necessarily select their data, the segment of their subject matter that they study, the aspect or direction of their approach and the methods and, perhaps, methodology they deploy. This is close to Max Weber's argument (see e.g. Parsons 1964 [1947], pp. 8-29).

We know, too, at a much cruder level, that social scientists insert their own perspectives, interpret data wilfully and reconstruct evidence within preconceived categories. At a more sublime level we also recognise that none of us are tabula rasa: we interpret our subject matter and our experiences through theories, concepts and language. We form theories of the world based on what has gone on before in thought, even when we are rejecting this thought because of better evidence or cannier insights. We think using language. The point I want to stress here is that these are not 'value problems' per se. These problems are both epistemic and sociological (i.e. contained within the domain of sociology of knowledge). Nor are these problems confined to the social and human sciences and ethics. In fact much 
of our knowledge of these problems of knowledge was generated by investigations in the philosophy of science (see e.g. Kuhn 1957, 1996 [1962]).

Instead of pondering these separate questions I will focus exclusively on the structure of the NOFIA, which we will see is the ultimate ground of the fact-value dichotomy. David Hume assumes the seminal - indeed almost iconic - position in the NOFIA tradition (MacIntyre 1966, p. 246). In fact it goes by the names Hume's Law, Hume's First Law, Hume's Guillotine or Hume's No-bridge Principle. Sometimes the phrase 'naturalistic fallacy' is used to describe the error committed by those who break Hume's Law. However, this is not quite correct, though there are some similarities. The naturalistic fallacy was, in GE Moore's Principia Ethica, the error committed by those who endeavoured to define 'good' in specific, natural (factual) terms.

At any rate a brief passage from Hume's 1739-40 work A Treatise of Human Nature: Being An Attempt to Introduce the Experimental Method of Reasoning into Moral Subjects (Book III Part I Section I) is given pride of place. Karl Popper for one was in no doubt about its significance:

Perhaps the simplest and most important point about ethics is purely logical. I mean the impossibility to derive nontantological ethical rules - imperatives; principles of policy; aims; or however we may describe them - from statements of facts. Only if this fundamental; logical position is realized can we begin to formulate the real problems of moral philosophy, and to appreciate their difficulty. (Popper 1948, p. 154; my emphasis)

\section{The NOFIA: a formal statement of the 'no ought from is argument'}

I will now try to set out the NOFIA formally. At bottom it includes three classes of statements, with each containing two clauses (I will use letters and numbers to make identification easier). Moreover I will include post-Hume adaptations to arguments within the tradition, such as not restricting the notion of fact to the Humean 'sense impression'. These then are the basic propositions on which the NOFIA rests:

F1 Descriptions of the states of affairs, events and relations in the world state facts; and

F1.1 Facts provide cognitive material (are objects of thought, inference, reason, may be judged true or false etc.); and

F1.2 Facts are reducible to experiences expressible in concrete physical terms; and

V1 Values express sentiments, feelings, preferences and attitudes and imply imperatives, prescriptions etc.; and

V1.1 Values are non-cognitive; and

V1.2 Values may be factored out from facts that we can experience (and theoretical terms) by a recursive process of radical decomposition; and

D1 A value cannot be derived from facts alone; and

D1.1 The NOFIA is a 'demonstrative' or deductive argument; and

D1.2 Whatever exists in the conclusion must exist in the premises (principle of conservation); therefore

C1 For a value to be derived from an argument presupposes that its value clause has done the logical work; and

C2 Given that ends are values, reasoning that does not fall foul of the NOFIA must be about means.

This is a fair rendition of the argument. I have tried pre-emptively to plug holes and counter-arguments with the subordinate clauses under F (fact), V (value) and D (deductive structure). For example, under V1.2 we can expand the notion of fact to admit 'theoretical terms'. These were terms admitted as devices by positivist philosophers of science to describe unobservable or non-experiencable entities (e.g. 
gravitational or magnetic fields, atoms, sub-atomic particles etc.) but that in themselves were not necessarily regarded as being real (or factual).

I must confess to having struggled to fit a general moral argument constructed according to the NOFIA into a simple symbolic form of deductive logic. Take the general modus ponens form, in which we might imagine $\mathrm{P}$ and $\mathrm{Q}$ as functions or algorithms that strip down (decompose) the complex structure of propositions in our natural language to plain F1.2 brute facts and V1.2 brute values:

$$
\begin{aligned}
& P(F) \\
& \stackrel{P(F) \rightarrow Q(V)}{\rightarrow Q(V)}
\end{aligned}
$$

Note that this works only because the statement of implication is conditional. The statement $P(F) \rightarrow$ $Q(V)$ cannot be general because it would allow facts to entail (or imply or lead to) values from the start. However, the NOFIA seems to work for conditional statements: 'if P then Q'. For example, we might translate this into a plain language form:

\section{Mistakes have been found in the draft of this paper $[P(F)]$ \\ If errors are found $[P(F)]$ then errors should be corrected $[Q(V)]$}

The blunders ought to be corrected $[Q(V)]$

Note that the form of deduction is not the problem. The same would be true of, say, a syllogism: If $\mathrm{P}(\mathrm{F})$ $\rightarrow$ then $\mathrm{Q}(\mathrm{F})$ \& if $\mathrm{Q}(\mathrm{F}) \rightarrow$ then $\mathrm{R}(\mathrm{F})$; given $\mathrm{P}(\mathrm{F}) \rightarrow \mathrm{R}(\mathrm{F})$. Note also that it is possible to insert a ceteris paribus clause into the structure to allow for contingencies. That is, $P(F) \rightarrow Q(V)$ CP would mean that errors should be corrected, other things being equal. Thus errors should be corrected unless they were deliberate; unless doing so would mean that you would miss a doctor's appointment that would save your life, etc. The structure also suggests that the argument seems to work when its content (semantics) involves following rules, obeying commands, honouring commitments, keeping promises and adhering to principles (i.e. in situation $\mathrm{X}$ do $\mathrm{Y}$ ). I will return to this point below.

Now it seems to me that the content of the argument belies our actual experience of working out what is right to do, what to value and how to live. It actually contradicts what we do: the reality of practical reason. It seems absurd to think that our moral judgements can be radically quarantined from the facts of the world in which we live and from the way in which we consider ethical questions. Yet this is precisely what the argument does. Facts participate in the argument, but their role is curtailed. As Kovesi put it, 'the relevant facts of the situation are not given as reasons for one's acts or for one's decisions. The relevant facts of the situation serve only to enable us to recognize that there is a case that falls under a principle', rule, command or obligation (1967, p. 101; see also pp. 77, 97-98, 110, 114, 142-43).

Typically, in contrast, when posed with a moral judgement we consider the problem in its various aspects. In most situations we face it is simply insufficient to rely on received moral principle. Straightforward cases such as crimes might permit a moral principle to be deployed, but even so we are often required to ponder our judgements (e.g. 'murder' by victims of domestic violence). Typically we reason: argument, evidence and data assist our thinking and shape our conclusions. In many instances we think the issues through 'publicly', with family and friends or socially. We often face criticism and we reply to it.

Moreover we are active agents in our moral lives and not mere automatons who typically fall back on higher authority or lurch forward from some predetermined bio-evolutionary disposition. The 'fall back' position arguably describes the approach of those who defer, for example, to authority. The 'lurch forward' position I take to be Hume's view roughly expressed: we are predisposed to follow the moral rules that have evolved over time and that 'conduce to utility'. In both cases there seems an underlying pressure to conform to a model of deductive reasoning. What is missing in both instances is the appeal to reasons, arguments and facts. Yet if we think about what we actually do in exercising practical reason, the missing elements are essential. 
Unfortunately I fear that these evidentiary arguments from the practice of making 'ought' judgements and decisions will be insufficient to satisfy the doubters. Therefore I will set out my reasons for rejecting the NOFIA formally and, in the following sections, I will explore two cases. The first will be the position presented by John Searle that oughts can be and are commonly derived from facts describing the world. The second will be a position associated today with the critical realist school of philosophy, namely that the notion of explanatory critique of false views demonstrates how normative conclusions can be derived directly from facts about the world. Before I do so, however, I will make a few remarks in the next section about means-ends reasoning (see $\mathrm{C} 2$ above) and the status of noncognitivism (see V1.1).

\section{Means, Ends and Non-Cognitivism}

Logically there is no valid reason that 'ought' judgements cannot be about ends: e.g. coming to a conclusion such as 'we ought to think that $\mathrm{X}$ is a good end for human development', 'we ought to pursue $\mathrm{X}$ as an end', etc. Indeed an economics that did not consider ends, as proposed by Robbins, is an oxy-moron. There is always an end, and enacting any set of means (value free or not) is instrumental in producing and reproducing - in fact embodying - the 'given' ends. We cannot simply ignore the moral implications of means by forbidding ends from playing an active part in our economic thinking. Hiving the 'ends question' off to another domain will not help. The problem we continue to face is a version of the familiar question: 'do the ends justify the means?' We will still be called to account by some or other theory of ethics to justify the means: either consequentially or in themselves. Otherwise what was Nuremberg, to use an extreme example, all about?

We surely cannot bifurcate our lives into value-free and value-active domains, and it is odd that we ought even to try to do this with our lives as social scientists (e.g. separating talk about economic matters from talk about the non-economic). Sen parodies this split in his paper 'Description as choice', which was first published in 1980:

The debunking of welfare economics that can be seen in such works as Lionel Robbins' The Nature and Significance of Economic Science kept prescriptive studies somewhat immersed in a pool of apology from the mid-thirties until relatively recently. Welfare economics was for a long time the 'untouchable' in the community of economics and when economists spoke 'qua economist' - to use that lovely expression brought into circulation by positivism - they tried to speak in a value-free 'scientific' language, with 'expletives' deleted. Welfare economics was seen as the subject, if not of expletives, at least of emotive utterances, which the cool positivist scientists found 'meaningless' in terms of their narrow theory of meaning. (1982 [1980], p. 443)

The alternative that Sen has pursued is, at a very fundamental level, to posit enquiry into the grounds of human flourishing as a core (factual) research endeavour: “ "...ascertain the function of man" and then proceed to explore "life in the sense of activity" as the basic building block of normative analysis" (1999, p. 73; see also 1993). Now if the 'function' of human beings (what we are and what we need to flourish) becomes our $\mathrm{P}(\mathrm{F})$ and our end, and if we proceed by establishing that, in the lives we lead ('in the sense of activity'), certain valued capabilities are required for $\mathrm{P}(\mathrm{F})$, then we are well on the way to having derived our Q(V) (see also Bhaskar 1994, pp. 110-14). Deriving values from an objective enquiry into human ends is what Sen has done in general terms and what Martha Nussbaum (inter alia 2001, 2000, 1999, 1993), in particular, has proposed in a more specific list of 'central human capabilities'.

Note that, having set out the argument in this way, our value statements - statements of central capabilities and rights such as freedom, nourishment, shelter, security and the like - are framed as means of facilitating the human function and its flourishing. What this says is that nothing is inherent about means that renders them value free and factual and therefore amenable to reason. Nor is there anything inherent about ends that make them the opposite. The fact that most ethical arguments seem to concern the rightness of means corroborates this point of view. 
A contingent inference from V1.1 in the formal statement of the NOFIA is that values are relative to their holders. I have noted this earlier. The argument that non-cognitivism implies relativism can be made plausibly. Supporters of the NOFIA may baulk at the inference or, like Hume and Friedrich von Hayek (see e.g. 1972 [1960], p. 63), may present alternative grounds for holding a non-relativist position. However, it is a predicament within the received view (Putnam 2002, pp. 41-45; Walsh 2000, pp. 6-9). Walsh and Putnam explain that, in philosophy, the grounds for supporting the fact-value dichotomy have shifted in recent years, and they have shifted in ways that make them more relativist.

This is especially so of Bernard Williams's arguments. Putnam asks 'just what sort of dichotomy the new dichotomists $d o$ offer'. He notes that a statement such as 'Peter is cruel', for Williams, 'can be true "in the very same sense in which 'snow is white' is true, while still being an ethical utterance". Putnam points to the key, which is that statements in ordinary language, such as 'snow is white' or 'grass is green', are not regarded by philosophers such as Williams 'as possessing the highest kind of "truth"' (2002, pp. 41-42). Walsh argues:

[I] I say that grass is green, for example, I certainly speak the truth; but I do not speak what he [Williams] calls the absolute truth. I do not describe the world as it is 'anyway', independently of any and every 'perspective'. The concept 'green' (and possibly the concept 'grass' as well) are not concepts that finished science would use to describe the properties that things have apart from any 'local perspective"”. (Walsh 2000, p. 8; citing Putnam 2002, pp. 41-42 (originally Putnam 1993); my emphasis)

According to Putnam, Williams 'does not deny that ethical sentences can be true or false'. This clearly represents an advance on traditional positivism. However, what Williams denies is that ethical sentences "can be true or false nonperspectively. Thus the position Williams defends has been renamed: instead of "noncognitivism" it is called "relativism".' (2002, p. 41)

Hand in hand with a relativist approach to values, Williams and those like him have a fundamentalist approach to facts. This is that the ultimate facts Walsh mentions are those expressed in the language of physics. Where this language gets us in the social sciences, or in navigating our respective ways through the problems of daily life, is anyone's guess. Some very real (factual) and important things simply get lost in descriptions that try to factor out the social and a fortiori ethical world we inhabit. Try, for instance, to convey the horror of war in the language of physics. You will not remotely be able to achieve the task without using value words descriptively. Horror is just one such word.

\section{Formal statement of objections to the NOFIA}

What then are the formal arguments against the NOFIA (whether it concerns ends or means)? I will present seven and relate them to the alpha-numerical outline of the NOFIA above. The objections are:

O1 The NOFIA presents an impoverished and reductionist view of facts and values (re all Fs and Vs):

O1.1 Descriptions of the world can state values and not just facts, such as 'Paula is cruel' or 'to do $\mathrm{x}$ and $\mathrm{y}$ in circumstances $\mathrm{z}$ is murder' $(\mathrm{F} 1, \mathrm{~V} 1)$;

O1.2 Facts and values are entangled, and decomposition of fact-value terms is wrongly eliminative: i.e. it eliminates essential features of the object to which the term refers $(\mathrm{F} 1.2, \mathrm{~V} 1.2)$;

O1.3 Facts and values can both provide cognitive material, which is to say that they are objects of thought, inference, reason and may be judged true or false etc. (F1.1, V1.1);

O1.4 Some facts, like values, are abstract entities irreducible to experiences expressible in concrete physical terms (F1.2, V1.2);

O2 Some factual events or states of affairs (of the rule, command, commitment, promise and principle kind) create desire (value) independent reasons for action that in themselves imply imperatives (D1, C1); 
O3 A commitment to truth, as a supervening epistemic value, permits values to be deduced from facts in arguments employing explanatory critique (C1); and

O4 The form of the NOFIA is false because 'ought' judgements in moral, practical reasoning are analogically 'abductive' (to use Charles Sanders Pierce's term) not deductive or, for that matter, inductive (D1.1).

It is important to recognise that all but $\mathrm{O} 4$ of these objections do not concern the form of the NOFIA. They are about its content. There is a very sound reason for this. It is to emphasise that premise D1.2, the principle of conservation ('whatever exists in the conclusion must exist in the premises'), if treated as a mere rule of logic, gives only trivial results at best. At worst it is no proof at all. John Searle makes this argument very strongly in his Rationality in Action, stressing that logical 'validity does not derive from the rules of logic ... in real-life reasoning it is the semantic content that guarantees the validity of the inference, not the syntactical rule' (2001, pp. 19-21). In other words, using the modus ponens again, only if the statements permit the inference will the statement be valid. Any nonsense can be made to fit the modus ponens form. Putnam comments similarly that the NOFIA:

... turns not on any feature of the form of the statement but rather on an understanding of its content. Nor did Hume himself (or any of his readers) understand the claim as one about the canons of formal inference. Rather, Hume assumed a metaphysical dichotomy between 'matters of fact' and 'relations of ideas' ... What Hume meant was that when an 'is' judgement describes a 'matter of fact' then no 'ought' judgement can be derived from it. Hume's metaphysics of 'matters of fact' constitutes the whole ground of the alleged underivability of 'oughts' from 'ises'. (2002, pp. 14-15)

Therefore it is appropriate to concentrate on the content of the NOFIA: its metaphysics, as it were. We can be clearer about its substantive grounds if we do so. We can also say that it fails if any of its particular grounds are incoherent (i.e. such as covered by objections O1.1-1.4 and O2) or if general objections are successful (O3 and $\mathrm{O} 4)$. Grounds fail and objections are successful if instances either fail or succeed, respectively.

\section{Searle's "How to Derive "Ought" From "Is"،}

I will discuss O2 in this section and then move on to consider O4 and O3 in that order. In 1964 John Searle published "How to derive "ought" from "is"" in the Philosophical Review (1964, pp. 43-58; 1967 [1964], pp. 101-14). While I will take some liberties with Searle's argument my presentation is faithful to his intent. In essence it is an argument from performative utterance, namely that to utter certain words actually creates or performs the act in question. No additional conditions need to be satisfied for the act to have been performed in fact.

For instance, to say to a waiter in a coffee shop 'please get me a coffee' is to perform the act of requesting coffee. It is, more formally, to order coffee: i.e. to perform the act of ordering. In contrast for the waiter to say 'I get you a coffee' is not, in fact, to get a coffee. The difference between the two statements is reflected in the awkward grammar of the second. We need a different form of the verb in order to make sense of it. 'I will get you a coffee' or 'I got you a coffee' are statements we can understand. Correcting the grammar amounts to inserting a condition of factual verification or falsification into each statement. In Searle's terminology, we have changed the verb to create 'conditions of satisfaction' of the proposition, statement or sentence. That is, it might or might not be true that the waiter will get or got the coffee. In any case neither statement in itself constitutes the act of making coffee in the way that performing the speech act 'Please get me a coffee' constitutes the act of making an order or a request.

With an understanding of performatives we can better appreciate Searle's argument. The particular example he uses is the statement of fact that 'Jones uttered the words "I hereby promise to pay you, 
Smith, five dollars"“. Intentional acts such as promising, making contracts and so on create constitutive obligations. That is, they constitute or entail obligations merely by becoming facts. To make a promise by stating it (an 'is'), other things being equal, is to create an obligation (an 'ought'). This obligation exists whether or not the promise is honoured. We do not need an additional value statement such as 'Promises ought to be honoured' in order to create the obligation. The reason is that the commitment (the 'ought') exists independently of its conditions of satisfaction.

Just as we can readily understand the notion of an unsatisfied order or request for a coffee we can understand the fact of an unfulfilled promise to make us one. That is, the 'ought' is entailed in the promise itself not in its execution or in a meta-statement that 'the execution ought to be executed'. Indeed were the latter to be true we would get an infinite regress: that 'the execution ought to be executed' ought to be executed, and so on. In short just to promise is to perform an act of commitment. An act of commitment is an 'ought'.

Note that performative mis-statement is covered by the ceteris paribus clause. To declare falsely 'I promise to tell the truth, the whole truth and nothing but the truth' in a Nazi court arguably would create no obligation, if to be truthful would condemn Jewish, social democrat and communist acquaintances to the camps. I distinguish such instances from those in which it is manifestly necessary to break a promise because observing another conflicting moral principle is more important. A doctor is right, other things being equal, to break a promise to take her son to a rock concert in order to save the life of a patient. 'Other things being equal' here might include 'unless an equally competent practitioner were on hand to save the patient and the doctor volunteered merely to avoid the loud music'. In any case the doctor had an obligation and broke it, irrespective of whether or not she was right to do so.

Significantly, because of their public character, which is inherent in their being spoken or written in a language, we invest many performatives with social, normative and ethical status. Some, in Searle's vocabulary, become 'institutional facts' that often entail binding commitments. Therefore to state a fact, such as 'Earlier this week I promised that I would finish a paper and bring along 25 copies to the History of Economic Thought Society of Australian Conference', is sufficient for me to acquire the obligation that 'I ought to finish this paper and bring along 25 copies'. In that peculiar part of the social world inhabited by academics, operating as it does under its own sub-set of social and institutional norms, a promise to 'deliver a paper' attracts certain rights and obligations. The rejoinder that my promise already contained a 'valuey' word that implies an 'ought', namely 'promise', is precisely the point. It is gratuitous to add another clause that says something like 'promises ought to be kept', because the mere fact that I promised is what creates the commitment to honour that promise. In the academic world my commitment attracts additional institutional status.

Note that for the 'Searle' and 'conference paper' arguments to hold deductively it is entirely sufficient that I promised to complete this paper and that Jones promised to pay Smith five dollars. The 'ought' conclusions make specific in each case the general statement that promises entail commitments. Note also that, while the words 'promises' and 'commitments' are ethical words, the general statement 'promises entail commitments' is, to my mind, neither a value judgement nor a tautology. It is a factual statement of the meaning of the word promise. Moreover that Jones and I promised are facts entailing commitments irrespective of our subsequent desires: me, as I type while I have a pounding headache, and Jones as he squanders his means of repayment in a slot machine and utters a torrent of expletives, including 'damn you Smith, I take it all back!'

Perhaps I should let Searle speak for himself, for the following quotation will be useful later when we discuss explanatory critiques:

... the ability to perform speech acts ... [contains] the potential for desire-independent reasons for action, indeed it inevitably has the requirement of desire-independent reasons for action, because just about every speech act involves a commitment of some kind or other. The famous examples are speech acts like promising, where the speaker is committed to carrying out a future course of action, but asserting commits the speaker to the truth of the proposition asserted, and orders commit the speaker to the belief that the person to whom he 
or she gives the order is able to do it, to the desire that he or she should do it, and to permitting the hearer to do it ... The bizarre feature of our intellectual tradition, according to which no set of true statements describing how things are in the world can ever logically imply a statement about how they ought to be, is that the terminology in which the thesis is stated refutes the thesis. Thus, for example, to say that something is true is already to say that you ought to believe it, that other things being equal, you ought not to deny it. (2001, pp. 147-48; see also pp. 29, 182-83)

This just touches the surface of Searle's arguments. For example, Searle's purpose above has not been to suggest that the deductive model is appropriate. Rather he uses it to point out problems with the NOFIA model (1967 [1964], p. 102 n. 1). Indeed Searle thinks that there cannot be a deductive model of practical reason (2001, chapter 8). Here I can only point readers to a number of recent works (see e.g. Searle 2001, 1999, 1997, 1995).

Similarly to substantiate my objection at $\mathrm{O} 4$ - namely that the form of the NOFIA is false because 'ought' judgements in moral or practical reasoning are analogically 'abductive' (to use Charles Sanders Pierce's term) not deductive or, for that matter, inductive - would require much more space than I have. It is a case in which saying less is likely to be clearer, so I ought to say less, save to quote Pierce briefly:

[Induction] can never originate any idea whatever. No more can deduction. All the ideas of science come to it by the way of Abduction. Abduction consists in studying the facts and devising a theory to explain them. Its only justification is that if we are ever to understand things at all, it must be in this way. (1867, vol. 5, par. 145; see Lawson 1997, p. 294 n. 14)

Nevertheless let me touch on the subject by opening with these questions: Does your ethical thinking and practical reasoning follow a logically valid deductive form? Is it of the kind referred to above that sequesters oughts from facts and proceeds to deduce imperatives from antecedent moral principles alone? If you are like me and find this account intuitively false, you will still be likely to need more meaty argument. Thus I offer the following brief reasons:

O4.1 To use the word 'abductive' in this context is analogical. In theoretical and scientific reasoning, 'abduction' means that we opt for the explanation that might best explain the facts ('inference to the best explanation'). To do so a scientist would consider the facts and 'draw heavily' on pre-existing theories, experiences, beliefs and perspectives (Lawson 1997, p. 212). Analogically we can say that we make our practical moral decisions in ways that best fit the circumstances. In doing so, we appraise both the facts and our moral thoughts and sensibilities. First, in applying moral principles, we have to analyse the circumstances to see whether they apply in fact. Second, and this is much more common, we operate in circumstances in which moral principles and attitudes conflict and in which the facts are complex. In other words we operate in open systems. We are forced to weigh evidence, see whether this or that principle applies and engage in critical argument with ourselves and with others. 'The arguments from facts to values are more like evidential or scientific arguments than deductive arguments unsurprisingly, for values exist in open systems, and value-judgements are normic, always (or almost always) holding other things being equal.' (Collier 1994, p. 170; see also Collier 1998 and Searle 2001, pp. 253-54)

O4.2 In real life we do not have the luxury of ceteris paribus to absolve us of decision making responsibility. Relying on strict observance of moral principles as moral rules - as, perhaps, in extreme forms of deontological ethics that privilege certain rules over others - in effect imposes a form of closure on the open systems in which we operate. Only in a closed system that avoids O4.1 type problems might a deductive argument apply strictly. Similarly Searle's argument above regarding commitments, if interpreted strictly and without a ceteris paribus clause, imposes closure.

O4.3 "There are few such "moral principles", at least fewer than one might expect. Their form is " $\mathrm{X}$ is right (or wrong)" or "X ought (or ought not) be done" ... Of course we can judge an unlimited number of actions right or wrong if we state the relevant facts of the situations in which they are performed. Without that the act may or may not be right. What we mean by saying that the act may or may not be 
right is that its rightness depends on the relevant facts of the situation in which they are performed.' (Kovesi 1967, p. 104) Kovesi goes on to explain that the fact that we do have moral conflicts and dilemmas means that we have to have reasons for our judgements. This 'illustrates the fact that moral reasoning is not deductive ...' (Kovesi 1967, p. 114).

In each of the above points we can see that facts play a very active role. Indeed value terms such as murder describe facts: indeed value terms are abstractions constituted by but not reducible to the facts they describe. Fact-value entanglement is only part of the story. Fact dependence of values is the other. To make this point I will summarise O4.1-O4.3 somewhat differently. For this it will be sufficient to consider an additional practical question: What accounts for the fact that in our practical moral deliberations we are, in effect, always asking ourselves 'why' about the 'ought' statements?

The answer to this question is straightforward. Contra both Hume and the particular rule following 'rationalists' against whom he appeared to be arguing there is a need to justify our actions with reasons. Our actions are not derivatives of disposition, nor are they deductions from pure reason. Moreover our actions must be justified in a particular way: they cry out for reasons based on factual grounds. We ask 'why?' when we are told we ought to follow a certain moral principle because we first must judge whether the principle is apposite to the facts of the situation. We ask 'why?' because the facts will often be prescriptively unique, in the sense that they will constitute states of affairs and events that are, by analogy with antecedents, qualitatively different and distinct.

Of course, this is to say more than merely to acknowledge that every new set of facts will be unique. We never step into the same river twice, as Heraclitus is supposed to have said. In contrast to prescriptively unique situations some circumstances will be analogically of a kind with antecedents such that it is appropriate to apply a given moral principle or principles. Yet the question will always be the same, 'why?' How are we to know one way or the other? The answer is that we must be able to describe the facts in a sufficiently complete way in order to be able to make a judgement whether the situation is analogically of a kind or is prescriptively unique.

Clearly, in prescriptively unique situations, we ask more than just why a given principle is applicable or not. Here we must work out what to do, or what to prescribe, in the face of facts that challenge existing moral notions. Given principles might not apply, apply only partly or apply inadequately. Such situations are exponentially more complex because existing principles may conflict and conflict with developing notions. We must reason our way out of these dilemmas, which are themselves fact dependent: i.e. the new terrain of facts on which we find ourselves has created them. This tells us also that even complete moral notions that have become moral principles are never strictly a priori, however long they may have been with us. They have histories and origins in the world we inhabit. That such principles have the power to affect our actions attests to their vivacity and their relevance to the world we inhabit. Irrelevant moral notions wither. The test of relevance is essentially factual (Kovesi 1967, passim).

To conclude this section I will say a few words on why John Searle argues that there can be no deductive logic of practical reason. As above I will label this objection:

O4.4 Unlike 'theoretical reason', which is about beliefs, practical reason does not and cannot provide an entailment relation between the premises and the conclusion(s) of a deductive argument. There is a 'gap' between premises and conclusion. We may choose to act otherwise than a valid argument suggests we ought to act. A 'person with a desire is not committed to the satisfaction of that desire in the same way that a person who holds a belief is committed to the truth of the belief' (Searle 2001, p. 266-67). Similarly 'a person who has an intention is not committed to intending to achieve all of the consequences of the achievement' of her or his intention (2001, p. 267).

Partly this is because our practical reasoning occurs in open systems. Alternative premises exist and conflict, as do alternative actions. Partly it is to do with the problem of 'akrasia', or weakness of will, and no amount of logic can entail that we will act under its direction (see also Putnam 2002, pp. 43, 
71). Searle's argument is convincing (2001, chapter 8), and it further undermines the NOFIA because it removes its deductive structure.

\section{Explanatory Critique: Truth as Supervening Epistemic Value}

This final section will explore the objection to the NOFIA depicted at O3 above, namely that a commitment to truth, as a supervening epistemic value, permits values to be deduced from facts in arguments employing explanatory critique. This means of overcoming the fact-value dichotomy comes principally from the work of Roy Bhaskar, though there are antecedents in the work of Marx and Maurice Dobb in economics (see esp. Dobb 1973, chapter 1). Bhaskar's argument from critique is in various works by himself, his collaborator Andrew Collier and others from the critical realist school. In addition some critical realist writing can be opaque and rely upon an esoteric vocabulary. Therefore I will draw from the clearer expositions, which can be found in Archer et al. (1998).

An explanatory critique starts by observing a set of prevailing ideas or ideas that tend to be dominant in society. In the process of studying these ideas we necessarily study what the ideas or theories refer to or are about. In the following the 'transitive dimension of knowledge' (i.e. knowledge, belief or theory) refers to or is about 'the intransitive dimension of knowledge' (i.e. the world of experiences, actual events and states of affairs and the underlying mechanisms that generate them). The last point can be stated forcefully in reverse and applied to the study of society: to study society (the intransitive dimension) will necessarily involve studying the intransitive dimension (theories, knowledge and beliefs). This follows necessarily because we approach the world through the body of pre-existing language, concepts, beliefs and theory.

This, of course, does not warrant the extreme epistemic relativist conclusion that theories ipso facto are incommensurable and that no rational basis exists for choosing one theory ahead of another. It makes no sense to think that theories about different external subject matters will conflict. However, it is equally hard to imagine that theories that do clash, and thus are about something similar, do not have some common referents with at least some common or translatable empirical dimensions (irrespective of their different languages). At the very minimum it is rational to choose the theory that explains more of the empirical evidence more adequately. Post Keynesian and neoclassical economic theories, for example, do compete because they have something to compete about and against which their empirical adequacy can be evaluated and compared. Against Freud's theory of infantile sexuality both are truly incommensurable.

Now three possibilities present themselves, perhaps in order of their immediacy. First a set or subset of important prevailing ideas may be especially causally influential in shaping society or, at least, a significant part of it. We know that social scientific theories become part of their own object (society) and have reciprocal causal interactions with it. Thus the supposed 'crisis of Keynesianism' of the late 1960s to early 1970s gave sustenance to market liberal theoretical views such as those of Friedrich von Hayek and Milton Friedman. These theories in turn were influential in shaping the small government agenda in various countries, the consequences of which we now see in decentralised labour markets, privatised public services and infrastructure and fiscal conservatism.

Second studying ideas (ideologies) and society can expose how aspects of society necessarily depend for their reproduction on forms of false consciousness (or fetishism, to use Marx's term). That is, a set of false beliefs, if exposed as false, would also expose the aspects of society they concern and the wider society itself to criticism. This criticism consequently would lay the foundation for transformation of society or aspects of it. Were it shown that property right, as understood in British common and statutory law, were neither part of the natural order nor necessary for, say, democratic rights to be exercised, then public ownership of essential economic resources may well become a realistic proposition. The obverse (negative or absence) of this second possibility constitutes the third possibility. If it is possible to demonstrate that false ideas actually prevent transformation of the aspects of society to which they refer then those ideas can be said to affect this aspect of society by reinforcing it, buttressing it and absenting it from change. 
Given all that has been said above about the interdependence of ideas and their external objects, the fact that we can or have expose(ed) the falsity of ideas and explain(ed) their function as ideology means that we also necessarily criticise society. This is the essence of explanatory critique. In addition a further move is implied. If the dominant set of ideas about society is false, and society itself is thereby found wanting, then critique must suggest that society be transformed to remedy what is wrong about it. Thus, from facts about ideas and society ('is') a value ('ought') has been derived. The argument from facts to values is grounded entirely in the factual accuracy of the explanatory critique. From the fact that ideas about society are shown to be wrong, and because these false ideas and beliefs are interdependent with society itself, then society should be transformed accordingly.

Now this takes us to the heart of the argument, which I will summarise in the phrase 'the prescriptive force of truth'. It recalls the quotation from Searle (2001, pp. 147-48) above. In the words of Bhaskar and Collier:

\begin{abstract}
It might be said that the view that one ought to believe what is true is a value judgement. In one sense it is - it clearly has prescriptive force. But it is not an optional value judgement ... it makes no sense to say 'that is true, but I do not believe it'... So to be induced to believe something which is false does not just often cause other harm, it always is harm. Not of course by any means necessarily the worst harm that can befall a person, but harm none the less ... The theory of explanatory critiques is very far-reaching philosophically. Once we have a single valid fact-to-value (or is-to- ought) argument, the claim that such arguments are necessary fallacious falls, and the motive for resisting other sorts of fact-to-value argument is removed. Arguments from the conditions of human flourishing (one might add: not only human flourishing) come into their own. (1998, pp. 387-89)
\end{abstract}

The conclusion Bhaskar and Collier draw from the power of explanatory critique is "the possibility of extending realism into the realm of values and morality, finding an "intransitive dimension" underlying moral thought and moral change' that parallels the intransitive (real) dimension underlying 'scientific thought and scientific change'. Their aim is to reinforce 'a moral realism which is naturalistic in the sense that it does not look for real values in a Platonic world of ideas or a Kantian world of Noumena, but in the real world which we all inhabit' (1998, pp. 387-89).

At this point I wish to raise a problem I see in the way Bhaskar and Collier have argued their case. If we recall the three possibilities presented earlier showing how ideas and society are interdependent, we can note that Bhaskar and Collier hang their argument on the latter two. More precisely they stress the ability of society necessarily to generate false ideas as well as to depend on this process. This narrows their argument and seems to make its supports potentially a bit thin. It is sufficient in my view that society and false ideas are causally interdependent, from the level of our daily activity to the realm of social theory and practice. Therefore if the reproduction of existing social relations can be shown to depend on the false ideas, the falsity of these ideas implies a need to change society accordingly.

A related problem is whether it is possible that societies can indeed generate false consciousness necessarily. We can show that society can depend on false consciousness necessarily, but this is not the same as saying that it generates false consciousness necessarily. What it generates is the appearance upon which false consciousness depends. Consciousness is false in so far as our ideas do not correspond with the reality of social relations. The role of explanatory critique is intimately bound up with exposing (refuting) the way society often appears on the surface. It does this by exposing (revealing) the reality underlying how things appear. In the process we show that false consciousness is not necessary, though the appearance on which it depends might well be for the existing social relations to continue.

This distinction can be illustrated using a number of familiar appearance-reality contradictions. Perhaps the most common of these is the appearance that the Sun travels across the Earth's sky, rising and then setting. We may even infer from this appearance that the Sun orbits the Earth. Of course, we know that this is not true. However, neither in this nor other cases of appearance-reality contradiction do the real structures or relations of reality actually generate mistaken thoughts or theories. Rather, they generate an outward appearance to us: seen from our inadequate or flawed physical or intellectual perspective. 
This appearance can be entirely misleading, but it is we who do the 'work' in perceiving, in generating the perception. Similarly it is the work of humans that takes social appearances, such as the appearance of a free exchange between equal individual parties in labour markets, to be the limit of knowledge. This then becomes theory and contributes to the set of false beliefs about society (some of which are institutionalised in legal statute and judge-made law) that comprise its ideology.

I also wish to raise another problem. Critical realists tend to overstate the case for the originality of their approach to explanatory critique. I have already mentioned Marx (as do they) and Maurice Dobb. The latter's Theories of Value and Distribution Since Adam Smith: Ideology and Economic Theory (1973, esp. chapter 2) explores the roles of fact, value, concept and abstraction in economic thought and foreshadows forms of explanatory critique. Amartya Sen (1987) remarks that Dobb's work is thick with 'rich description', which captures essential features of the world and its events in factual yet evocatively moral ways. Sen also offers fascinating insights into the question of 'Positional objectivity' (2002 [1990], chapter 15; see also Putnam (2002) and Walsh (2000) on Sen and Dobb). Sen's essay, published in the recent collection Rationality and Freedom, considers ideas such as those in the preceding two paragraphs and approaches a subject that looks suspiciously akin to explanatory critique.

\section{Conclusion}

This paper has explained why the traditional fact/value, positive/normative and descriptive/evaluative dichotomies maintained by the 'positivist' approach are false. This approach has impoverished both ethics and (social) science as a result. The main reason, as the paper has attempted to demonstrate, is that the fundamental principle underlying the dichotomies, which is the formally structured argument that a value (ought) cannot logically be derived from a fact (is), is wrong. The paper also offers reasons to think that a moral realism, of a kind that combines facts and values in a common factually-grounded enterprise, is possible.

\section{References}

Archer, M, Bhaskar, R, Collier, A, Lawson, T \& Norrie, A 1998, Critical Realism: Essential Readings, Routledge, London.

Aristotle 1985, Nicomachean Ethics, trans. T. Irwin, Hackett Publishing Company, Indianapolis.

Bhaskar, R 1998, Possibility of Naturalism: A Philosophical Critique of the Contemporary Human Sciences, Routledge, London. 1994, Plato Etc.: The Problems of Philosophy and Their Resolution, Verso, London.

Bhaskar, R \& Collier A 1998, 'Introduction: Explanatory critiques', in M Archer, R Bhaskar, A Collier, T Lawson \& A Norrie eds, Critical Realism: Essential Readings, Routledge, London.

Collier, A 1998, 'Explanation and emancipation', in M Archer, R Bhaskar, A Collier, T Lawson \& A Norrie eds, Critical Realism: Essential Readings, Routledge, London. 1994, Critical Realism: An Introduction to Roy Bhaskar's Philosophy, Verso, London.

$\overline{\text { Dobb}}, \mathrm{M}$ 1973, Theories of Value and Distribution Since Adam Smith, Cambridge University Press, Cambridge UK.

Foot, P, ed. 1967 [1958-59], Theories of Ethics, Oxford Readings in Philosophy, Oxford University Press, Oxford.

Friedman, M 1953, 'The methodology of positive economics', in M Friedman, Essays in Positive Economics, University of Chicago Press, Chicago.

Hayek, FA 1960, The Constitution of Liberty, Gateway Editions, South Bend, Indiana.

Hume, D 1739-40, A Treatise of Human Nature: Being an Attempt to Introduce the Experimental Method of Reasoning into Moral Subjects, 3 vols, 1748, An Enquiry Concerning Human Understanding, 1751, An Enquiry Concerning the Principles of Morals, various edns, see e.g. 'Bibliography', in D Fate Norton 1993, The Cambridge Companion to Hume, Cambridge University Press, Cambridge UK, pp. 357-59.

Kovesi, J 1967, Moral Notions, Routledge \& Kegan Paul, London. 
Kuhn T 1996 [1962], The Structure of Scientific Revolutions, $3^{\text {rd }}$ edn, University of Chicago Press, Chicago.

1957, The Copernican Revolution: Planetary Astronomy in the Development of Western

Thought, Random House, New York.

Lawson, T 1997, Economics and Reality, Routledge, London.

MacIntyre, A 1966 [1959], 'Hume on "Is" and "Ought", in VC Chappell, ed., Hume: A Collection of Critical Essays, Anchor Books, New York, pp. 240-64.

Nussbaum, MC 2001, Upheavals of Thought: The Intelligence of Emotions, Cambridge University Press, Cambridge UK. 2000, Women and Human Development: The Capabilities Approach, Cambridge University Press, Cambridge UK. 1999, Sex and Social Justice, Oxford University Press, New York. 1993, 'Non-relative virtues: An Aristotelian approach', in NC Nussbaum \& A Sen eds 1993, The Quality of Life, Oxford University Press, Oxford.

Nussbaum, MC \& Sen, A eds 1993, The Quality of Life, Oxford University Press, Oxford.

Parsons, T 1964 [1947], 'Introduction', M Weber, The Theory of Social and Economic Organization, ed. T Parsons, trans. AM Henderson, The Free Press, New York.

Pierce CS 1867, Collected Papers of Charles Sanders Pierce, C Hartshorne \& P Weiss eds 1931-35, vols 1-6, Harvard University Press, Cambridge USA.

Popper K 1948, 'What can logic do for philosophy?' Aristotelian Society Proceedings, supplementary vol. xxii.

Putnam, H 2002, The Collapse of the Fact/Value Dichotomy and Other Essays, Harvard University Press, Cambridge USA.

1993, 'Objectivity and the science-ethics distinction', in A Sen \& MC Nussbaum eds 1993, The Quality of Life, Clarendon Press, Oxford.

Searle, JR 2001, Rationality in Action, Bradford, MIT Press, Cambridge USA. 1999, Mind, Language and Society: Philosophy in the Real World, Phoenix, Weidenfeld \& Nicholson, London. 1995, The Construction of Social Reality, The Free Press, New York. 1967 [1964], "How to derive "ought" from "is"“ in P Foot ed. 1967 [1958-59], Theories of Ethics, Oxford Readings in Philosophy, Oxford University Press, Oxford, pp. 101-14 (originally in the Philosophical Review (1964, pp. 43-58).

Sen, A 2002 [1990], 'Positional objectivity', in Rationality and Freedom, Harvard University Press, Cambridge USA. 1999, Development as Freedom, Random House, New York. 1993, 'Capability and well-being', in A Sen \& MC Nussbaum eds 1993, The Quality of Life, Clarendon Press, Oxford. 1987, 'Maurice Herbert Dobb', in J Eatwell, M Milgate \& P Newman eds, The New Palgrave: A Dictionary of Economics, Macmillan, London. 1982 [1980], 'Description as choice', in A Sen, Choice, Welfare and Measurement, Oxford University Press, Oxford.

Walsh, V 2000, 'Smith after Sen', Review of Political Economy, vol. 12, no. 1, January, pp. 5-25. 